У, $\triangle \mathrm{K} 347.97 / .99$

ББК 67.71

DOI 10.22394/1682-2358-2019-6-73-79

A.P. Yakovleva, Candidate of Sciences (Law), Docent of the Civil Law and Procedure Department, Povolzbsky Institute of Management named after P.A. Stolypin, Branch of the Russian Presidential Academy of National Economy and Public Administration

I.A. Blinkov, post-graduate student of the Civil Law and Procedure Department, Povolzbsky Institute of Management named after P.A. Stolypin, Branch of the Russian Presidential Academy of National Economy and Public Administration

\section{PROS AND CONS OF ELECTRONIC JUSTICE: FINDING A BALANCE}

The application of digital technologies in civil proceedings is considered. Electronic appeals to the courts, electronic notifications and calls, and research into electronic evidence are studied. Regulatory and legal acts, acts of clarification of law, and instructions for judiciary employees are analyzed. Collisions of the legislation in force are revealed and arguments are out forward to amend the legislation accordingly.

Key words and word-combinations: electronic justice, digital technologies, electronic signature, "Internet” network.
А.П. ЯковлеВа, кандидат юридичеких наук, дочент кафедрьг гражданского праља и проиесса Поволжского института управления имени П.А. Стольпина - филиала Российской академии народного хозяйства и государственной служби ири Президенте РФ

(email: yakovleva-anna1@yandex.ru)

И.А. Блинков, аспирант кафедро гражданского праља и прочесса Поволжского инсmитута управления имени П.А. Стольпина филиала Российской академии народного хозяйсmва и государственной службь при Президенте РФ (email:blinkov.igon@list.ru)

\section{ПАЮСЫ И МИНУСЫ ЭАЕКТРОННОГО ПРАВОСУАИЯ: ПОИСК БАААНСА}

Аннотация. Рассматриваются вопросы применения цифровых технологий в гражданском судопроизводстве, в частности электронного обращения в суд, электронных извещений и вызовов, исследования электронных доказательств. Анализируются нормативно-правовые акты, акты разъяснения права, инструкции для работников аппарата суда. Выявляются коллизии действующего законодательства и приводятся аргументы относительно внесения соответствующих поправок в законодательство.

Ключевые слова и словосочетания: электронное правосудие, цифровые технологии, электронная подпись, сеть «Интернет».

\section{Ц} во все сферы жизии, вкмючая и суаопроизводство. Это порождает разиичные оценки Аанного направления развития процессуаль- 
ного законодательства. Некоторые авторы, например, А.В. Белоусов, отмечают общую недоработанность развития законодательства в указанной области [1] . С.В. Василькова полагает, «что проџессуальные риски во множестве имеются в сфере электронного правосудия и в Аанном случае связаны, например, с неразмещением судом предусмотренной информации на своем интернет-сайте, риском нарушения принџипов гласности и открытости в деятельности судов,

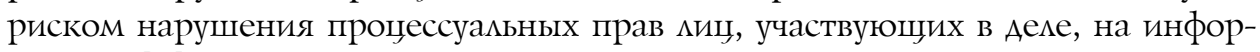
мацию» [2] .

Аругие, например А.Х. Вамеев, Е.В. Базилевских, наоборот, высказывают мысль о том, что «быстрота работы с базой Аанных, эргономичность хранения, Аоступность судебной информации, выносимых судом актов Аля обширного круга юридической общественности и других пользователей положительно характеризуют Аанный способ осуществления правосудия» [3]. Я.В. Антонов отмечает, что «подобно тому, как судебная система явцяется ключевым компонентом демократии, электронное правосудие явцяется важнейшим аспектом электронной демократии, и ее главная цель состоит в том, чтобы повысить эффективность судебной системы и качество правосудия» [4] .

Несомненно, в век гаджетов, цифровизации жизни в быту и Аеловой сфере невозможно даже представить, чтобы судебная система не воспринимала развитие технологий и отставала от современных реалий. Переход к цифровым технологиям имеет своей целью упрошение судопроизводства, что Аолжно привести к его ускорению сАелать суАебную защиту, с оАной стороны, Аоступнее, с Аругой - разгрузить суАебное производство от громозАкого, порой устаревшего и измишнего Аокументооборота. Не отриџая необходимости широкого внеАрения цифровых технологий в судопроизводство, полагаем, что повышение эффективности судебной защиты с помощью эмектронного правосудия возможно только при четкости законодательства и Аоступности использования цифровых систем.

Следовательно, чтобы выполнить функцию ускорения и Аоступности судопроизводства, современные проџессуальные нормы, внеАряющие цифровое судопроизводство, Аолжкны быть направлены именно на упрощение как суАебного делопроизводства, так и самого рассмотрения дела с применением современных технологий.

Электронное правосудие затронуло несколько сторон современного судопроизводства. Это, во-первых, возможность подачи различных обращений в суа в сети «Интернет» (этот оборот по АПК и ГПК); во-вторых, извешение участников судопроизводства посредством цифровых технологий; в-третьих, возможность вынесения акта правосудия на основе электронных Аоказательств; в-четвертых, применение видеоконференц-связи при рассмотрении дела или при совершении отдельных процессуальных действий. Рассмотрим некоторые из них.

Аанные нововведения вводииись в гражданское и арбитражное проџессуальное законодательство в разцичные периоды, определявшие этапы формирования электронного правосудия в указанных судах. Аидером в этом вопросе явияся Арбитражкный процессуальный кодекс (АПК)РФ. Так, в арбитражкный

74 Bulletin of the Volga Region Institute of Administration • 2019. Vol. 19. № 6 
процесс указанные электронные нововведения вошли в 2010 г. с принятием Федерального закона от 27 июля 2010 г. № 228-Ф3 «О внесении изменений в Арбитражный процессуальный кодекс Российской Федерации», затронувшего основные сферы арбитражного проџесса. В гражданский проџесс электронное правосудие и связанное с ним применение цифровых технологий вводилось поэтапно, в «щаАящем» режиме.

В гражканском судопроизводстве первым из элементов цифровизации стало внедрение видеоконференц-связи для допроса свидетелей, участия в судебном заседании миц, участвующих в деле, а также оказывающих соАействие осуществлению правосудия. В гражданском проџессе такая возможность появилась в 2013 году с принятием Федерального закона от 26 апреля 2013 г. № 66-Ф3 «О внесении изменений в Гражданский проџессуацьный кодекс Российской Федерации». Проблемами этих процессуальных

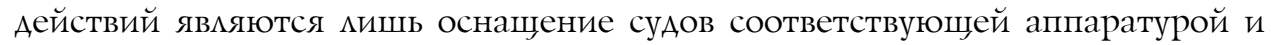
техническими возможностями, а также умение работников суда использовать данную связь. Некоторые ученые не связывают электронное правосуАие с оборудованием судов техникой, утверждая, что оснащение техникой и электронное правосудие не явмяется одним и тем же [1]. По нашему мнению, Аанная точка зрения правомерна, но необходимо отметить, что отсутствие технической оснащенности в судах не позволит осуществить те процессуацьные Аействия, которые составцяют электронное правосудие как таковое. Именно поэтому Аля его развития целесообразен комплексный поАход, который вкцючает в себя и вопросы оснащенности судов, и обучения работников аппарата суда, и непосредственно связанные с рассмотрением и разрешением дела по сушеству, поскольку «электронное правосудие - это способ осуществления правосудия, основанный на использовании информационных технологий» [5] .

Эмектронное обращение в суд общей юрисдикщии стало возможным три года спустя после начала применения видеоконференџ-связи в связи с принятием Федерального закона от 23 июня 2016 г. № 220-Ф3 «О внесении изменений в отдельные законодательные акты Российской Федерации в части применения электронных Аокументов в деятельности органов судебной власти». Этот формат позволяет подать в суА исковое заявление, заявление (в том числе о вылаче судебного приказа), жалобу, ходатайство посреАством заполнения формы, размешенной на офиџиальном сайте суда в сети «Интернет». По мнению практиков, «плюсов у данного нововведения масса, самый очевидный - экономия времени. Все-таки подать документы, не выходя из офиса ици Аома, Аорогого стоит, особенно Аля тех, кто постоянно в цейтноте. Причем саелать это можно круглосуточно» [6]. С этой точки зрения относительно времени и места обращения в суд не может быть никаких возражений.

Виртуальная действительность, безоговорочно вошедшая в нашу жизнь, позволяет, как верно отмечают исследователи, совершать действия в Интер-

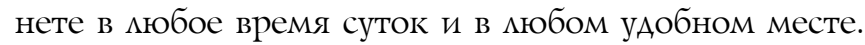

Вестник Поволжского института управления • 2019. Том 19. № 6 
ОАнако наряду с положительными сторонами использования виртуальных систем в судопроизводстве есть и отрицательные: многие правила возможици на заинтересованных циџ не только права, но и обязанности, которые, на наш взгляА, в некоторых случаях усложняют механизм подачи заявления в суа.

Так, документы, поданные в электронном виде, обязательно должны быть подписаны эмектронной подписью. ВиА эмектронной подписи (простая ици усияенная квалифицированная) зависит от типа документа. Например, исковое заявление, содержащее в себе ходатайство о наложении обеспечения иска, как и отдельное заявление об обеспечении иска, Аолжно быть подписано усиценной квалифиџированной электронной подписью. Казалось бы, данный порядок Аолжен уменьшить количество бумаг, но, на наш взгляд, уменьшая бумажные носители, он в разы увеличивает их электронные копии, изготовление которых невозможно без бумажных версий.

Например, подача искового заявления в электронном виде представитемем должна сопровожАаться электронным образом документа, в нашем примере - доверенности. Электронный образ документа - это переведенная в эмектронную форму с помощью средств сканирования копия документа, изготовленного на бумажном носителе, заверенная соответствующей эмектронной подписью (п. 1 постановления Пменума Верховного Суда РФ от 26 декабря 2017 г. № 57 «О некоторых вопросах применения законодательства, регулирующего использование документов в электронном виде в Аеятельности судов общей юрисдикџии и арбитражных судов», далее постановление Пленума № 57). Таким образом, доверенность, изготовменную на бумажном носителе, следует отсканировать, а скан доверенности заверить электронной подписью. Если речь идет о документе, который должен быть подписан усиленной квалифицированной электронной подписью, то нотариально удостоверенная доверенность, которая представцяется в электронном образе документа, подписывается усиленной квалифицированной электронной подписью нотариуса. Если квалифиџированная электронная подпись не требуется, то электронный образ документа заверяется простой электронной подписью киџа, обрашающегося в суд. В соответствии с приказом Судебного департамента при Верховном Суде РФ от 27 декабря 2016 г. № 251 (в ред. от 27 августа 2019 г.) «Об утверждении Порядка подачи в федеральные суды общей юрисдикции документов в электронном виде, в том числе в форме эмектронного документа» (дамее Приказ Судебного департамента № 251), кАючом к простой электронной подписи является учетная запись физического миџа в ЕАиной системе идентификаџии и аутентификаџии (ЕСИА) в инфраструктуре, обеспечивающей информационно-технологическое взаимодействие информаџионных систем, используемых Аля предоставмения государственных и муниципальных услуг в электронной форме, то есть на сайте Госуслуг. Аналогичные правила действуют и в арбитражном суде. К сожамению, данный порядок понятен не всем, особенно гражданам, не часто сталкивающимся с цифровыми технологиями, что может повлечь за собой их отказ от Аичной подачи заявлений в суА только по причине неуме-

76 Bulletin of the Volga Region Institute of Administration • 2019. Vol. 19. № 6 
ния использовать указанные новации, и вынудит в обязательном порядке обращаться за юридической помощью, которая оказывается на пиатной основе, что отнюдь не явцяется упрощением доступа к правосудию. Полагаем, раз речь идет об повышение эффективности правосудия, подробные и Аоступные разъяснения Аомжен дать Верховный Суа РФ.

Подача документов в электронном виде породица новое процессуальное действие, выполняемое работниками аппарата суда, которое не предусмотрено Гражданским процессуальным кодексом (ГПК) РФ, а регламентировано приказом Судебного департамента № 251 и Инструкциями по судебному делопроизводству в районном суде и соответственно в верховных судах республик, краевых и областных судах, судах городов федерального значения, судах автономной области и автономных округов [7; 8]. Это процессуацьное Аействие носит название отклонения документов, уведомление о котором в автоматическом режкиме отправляется в кичный кабинет заявителя с указанием, что Аокументы не могут быть признаны поступившими в суд (п. 4.4, 4.5 Приказа Судебного департамента № 251). Аанное проџессуальное действие - откцонение документов - не может быть обжаловано, что, по нашему мнению, явцяется ограничением доступа к правосудию.

Еще один вопрос, связанный с обращением в суд на интернет-портале, возникает при необходимости подтвержАения подиинности электронных образов документов бумажкными носителями (квитанция об уплате госпошмины, ордер адвоката и др.). Например, при подаче Аокументов в виде эмектронных образов и принятии их судом послеАний вправе потребовать

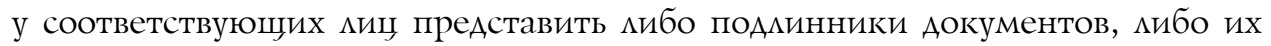
заверенные копии. Непредставление таких Аокументов может повцечь за собой оставление заявления без рассмотрения (п. 9 постановления Пкенума № 57). Несмотря на то, что Аанное разъяснение носит Аиспозитивный характер, представляется, что указанный порядок при его применении не будет явцяться упрощением Аокументооборота и не уменьшит количество Аокументов, представленных на бумажном носителе. Полагаем, что электронное обращение в суд могло бы быть освобождено от повторения документов на бумажном носителе.

Внедрение цифровых технологий в судопроизводство внесло еще оАно правицо, которое, на наш взгляА, является удобным, но его регламентация несколько Авойственная. Развитие цифровых технологий в системе пра-

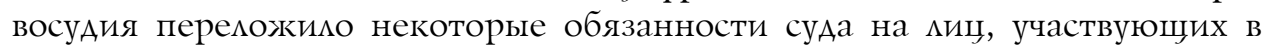
Аеме.

Речь идет об извещении миџ, участвующих в деле, посреАством современных среАств связи, и связанных с ними новыми правилами. Так, в арбит-

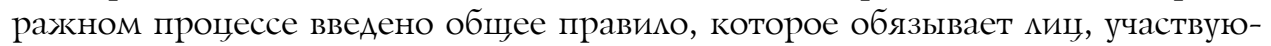
щих в деле, самостоятельно отслеживать движение дела в Интернете после получения первого судебного извещения. В соответствии со ст. 121 АПК РФ участники судопроизводства изначально извещаются судом копией судебного акта о принятии искового заявления к производству и возбужАении производства по делу на бумажкном носителе и в сети «Интернет». ОАнако, 
как отмечается в п. 15 постановления Пценума № 57, получением первого судебного извешения или первого судебного акта миџом, участвующим в Аеме, иным участником проџесса следует понимать получение, в том числе по электронной почте, судебного извешения кибо вызова в предварительное судебное заседание, судебное заседание и (или) копии опредемения по Аелу. После этого указанные миџа обязаны самостоятельно преАпринимать меры по получению информации о движении дела с использованием мюбых источников такой информаџии и Аюбых средств связи. Аиџа, участвующие в деле, несут риск наступления неблагоприятных последствий в результате непринятия мер по получению информаџии о движении дела (ч. 6 ст. 121 АПК РФ).

В гражданском проџессе такое императивное правило, за некоторыми искАючениями, установлено в отношении органов государственной власти, органов местного самоуправления, иных органов и организаций, явмяющихся сторонами и Аругими участниками гражданского процесса (ст. 113 ГПК РФ). Поэтому указанные субъекты уже четко представцяют себе способ их извещения.

В отношении Аругих участников гражданского судопроизводства такого правила нет. ОАнако, утверждается, что в п. 15 постановления Пиенума № 57 суд по заявлению мица, участвуюшего в деле, обязан направлять ему извешения, вызовы и иные документы, предусмотренные законом (их копии), в электронном виде. Аалее, в абз. 2 п. 19 постановления № 57, Пценум разъясняет, что согласие на извещение по эмектронной почте может быть выражено, в частности, посредством указания адреса электронной почтьи в тексте обращения в суд, а также при подаче обращения в суд в электронном виде посредством заполнения соответствующей формы, размешенной на официальном сайте суда в сети «Интернет». Таким образом, согласием является указание электронного адреса и/или заполнение электронной формы на портале. Никакого дополнительного письменного согласия на извещение по электронной почте Аиџа, участвующие в деле, не дают, что тоже вызывает вопрос, правильно $\Lambda$ это. К тому же в соответствии с ч. 2 ст. 131 ГПК РФ в исковом заявлении может быть указан адрес эмектронной почты, и миџо, указывающее свой электронный аАрес в заявлении, может и не подозревать, что дает согласие только на электронное извещение. Таким образом, предоставленное современным законодательством право подачи электронных документов в сети

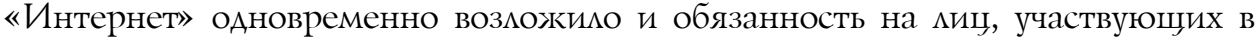
деле, самостоятельно отслеживать его движение, причем эти миџа могут и не подозревать об этом.

Аругое правимо извещения, имеющее менее скрытой порядок дачи согласия на его использование, существует в отношении СМС-сообщений. Отметим, что такой виА извещений прямо преАусмотрен только Кодексом административного судопроизводства (КАС) РФ и не указывается ни в ГПК РФ, ни в АПК РФ. Так, в соответствии с ч. 1 ст. 96 КАС РФ миџо, участвующее в Аеле, с его согласия может извещаться путем отправки ему СМС-сообщения. Суды этот порядок применяют, используя анало-

78 Bulletin of the Volga Region Institute of Administration 2019. Vol. 19. № 6 
гию закона, и извещают ииц, участвующих в деле посредством СМС-сообщений.

Приказом Судебного департамента при Верховном Суде РФ от 25 декабря 2013 г. № 257 (в реА. от 27 авг. 2019 г.) утвержден Регламент организации извещения участников судопроизводства посредством СМС-сообщений, кото-

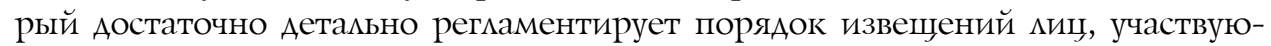
щих в деле, путем СМС-сообщений. В Регламенте указано, что такой порядок извещения осуществляется только с согласия участника судопроизводства, то есть на добровольной основе, о чем мица, участвующие в деме, Аают расписку. Полагаем, что данный порядок более правильный, прозрачный, поскольку миџо, собственноручно составмяющее расписку на бумажном носителе, четко представцяет себе, на что оно дает согласие и понимает последствия такого процессуального действия, в отличие от извешений по электронной почте, где согласие на данный вид извещения носит, по-нашему мнению, скрытый характер.

Итак, представляется, что электронное правосудие, несомненно, призвано облегчить и ускорить судопроизводство как в цемом, так и на этапе обращения в суА и извещения участников проџесса. ОАнако дмя достижения указанной цели необходим комплексный подход законодателя, включающий устранение комиизий и пробелов процессуального законодательства, а также унификацию норм различных процессуальных кодексов.

\section{Библиографический список}

1. Белоусов Д.В. Электронное правосудие и его роль в организации судебной защиты в России // Администратор суда. 2015. № 3. С. 20-22.

2. Василькова С.В. Доктринальный и практический аспекты применения категории «процессуальный риск» в сфере электронного правосудия // Вестник гражданского процесса. 2018. № 4. C. 87-95.

3. Валеев Д.Х., Базилевских Е.В. Система нормативных регуляторов «электронного правосудия» // Российская юстиция. 2019. № 8. С. 34-36.

4. Антонов Я.В. Конституционно-правовые перспективы развития электронного правосудия в России // Администратор суда. 2016. № 2. С. 10-15.

5. Интернет-интервью с Председателем Арбитражного суда Калужской области Сергеем Юрьевичем Шараевым. Электронное правосудие: итоги и перспективы. URL: http://www.garant.ru/company/cooperation/gov/action/regional/271319/\#ixzz5ri8cuj4j

6. Андреевская A.B. Арбитражные суды: электронное правосудие // Актуальные вопросы бухгалтерского учета и налогообложения. 2011. № 12. С. 88-92.

7. Об утверждении Инструкции по судебному делопроизводству в районном суде: Приказ Судебного департамента при Верховном Суде РФ от 29 апр. 2003 г. № 36 (в ред. от 21 окт. 2019) [Электронный ресурс]. Доступ из СПС «КонсультантПлюс».

8. Об утверждении Инструкции по судебному делопроизводству в верховных судах республик, краевых и областных судах, судах городов федерального значения, судах автономной области и автономных округов»: Приказ Судебного департамента при Верховном Суде РФ от 15 дек. 2004 г. № 161 (в ред. от 9 янв. 2018 г.) [Электронный ресурс]. Доступ из СПС «КонсультантПлюс». 